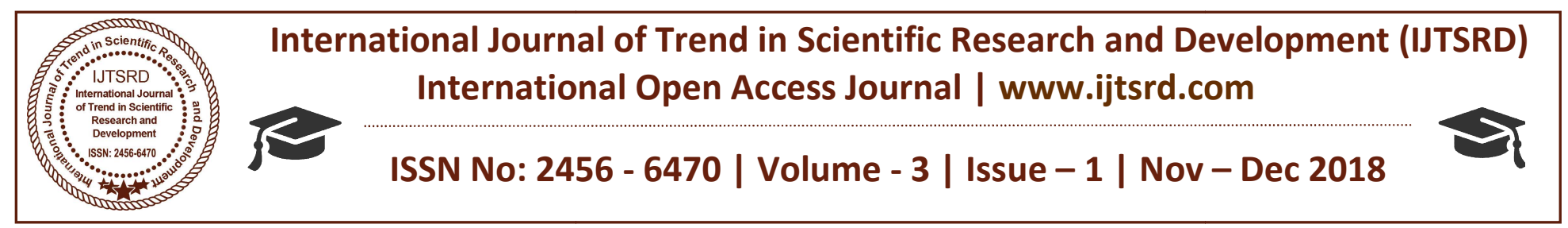

\title{
CFD Analysis of Solar Air Heater for Enhancenment of Heat Transfer Through Inclined Rib Roughness
}

\author{
Ajay Jain ${ }^{1}$, Prof. H. S. Sahu ${ }^{2}$ \\ ${ }^{1} \mathrm{PG}$ Scholar, ${ }^{2} \mathrm{Head}$ of Department \\ Department of Mechanical Engineering, MIT, Bhopal, Madhya Pradesh, India
}

\begin{abstract}
A 3-dimensional CFD analysis has been carried out of solar air heater to study heat transfer and fluid flow behavior in a rectangular duct of a solar air heater with one roughened wall having combination of circular and square transverse wire rib roughness. The effect of Reynolds number, roughness height, roughness pitch, relative roughness pitch and relative roughness height on the heat transfer coefficient and friction factor have been studied. In order to validate the present numerical model, results have been compared with available experimental results under similar flow conditions. CFD Investigation has been carried out in medium Reynolds number flow.
\end{abstract}

Average Nusselt number increases with an increase of Reynolds number. The maximum value of average Nusselt number is found to be 128.9646 for relative roughness pitch of $20 \mathrm{~mm}$ and for relative roughness height of $0.06 \mathrm{~mm}$ at a higher Reynolds number, 14000.

Average friction factor decreases with an increase of Reynolds number.

The range of parameters for this study has been decided on the basis of practical consideration of the system and operating conditions. The experiment has covered a Reynolds number ( $\mathrm{Re}$ ) range of 600016000, Relative roughness pitch (P/e) of 8, 10 and 12. Relative angle of attack $(\alpha / 90)=0.3333$. Results have been compared with the heated plate without roughness and with the earlier reported inclined rib under similar flow condition to determine the enhancement in heat transfer coefficient and friction factor.
KEY WORDS: CFD Analysis, Absorber plate, Enhancement Factor, Reynolds's No., Nusselt No

\section{INTRODUCTION}

The sun is the best source of energy. The little portion of sun powered illumination got by the earth is adequate for the presence of life. This illumination is changed over into various types of energy that are helpful in a wide range of uses. The various wellsprings of energy referred to exist have their root as the sun with the exception of atomic energy. The upsides of the sun have driven numerous researchers all through the world to inquire about on monetary methods for bridling its energy.

The sun is an inexhaustible source of energy. It is moderately simple to saddle and is naturally amicable. These focal points make it a main possibility for the arrangement of energy to the entire world. Coal and oil have been utilized for a long time now. The consuming of these petroleum derivatives prompts discharge of carbon dioxide, sulfur and nitrous oxides. Carbon dioxide is a solid ozone depleting substance that causes a dangerous atmospheric devation. Sulfur and nitrous oxides are changed over into acids in the climate and are inevitably accelerated as corrosive rain, which is perilous to creatures and plants. Atomic energy is not ecologically well disposed and has disadvantages since the atomic power plants are costly to manufactured and keep up. Besides, the capacity and transfer of atomic waster has not been settled yet. Numerous sunlight based gathering gadgets are as of now being used all through the world. These gather sun based radiation and change over it into valuable energy, for example, warmth or power. Photograph voltaic gadgets utilize semiconducting materials to change over daylight specifically into power. Photograph warm gadgets as 
a rule called sun powered authorities change over sun based radiation into (warm transformation). Sunlight based authorities are utilized to warm water and air inside structures at bring down temperatures.

Solar collectors utilized for warming water and cooling are primarily of flat-plate sort. A flat-plate sun oriented gatherer is straightforward and cheap. The most essential and basic piece of the flat plate authorities is the safeguard surface. With a specific end goal to boost the yield from the sun based gatherers, the safeguard ought to be frightfully particular. It ought to ingest however much of the approaching sun powered radiation as could be expected and in the meantime hold the gathered warmth. This implies it should display high sun oriented absorptance and low warm emittance. Warm misfortunes because of conduction, convection and radiation affect the proficiency of sun oriented safeguards. Other attractive properties of sun powered safeguards are that they ought not debase fundamentally amid the lifetime of the authority and that they ought to withstand cruel natural conditions.

\section{LITERATURE SURVEY}

\begin{tabular}{|c|c|c|c|c|}
\hline $\begin{array}{l}\text { SR. } \\
\text { NO. }\end{array}$ & TITLE & AUTHORS & YEAR & METHODOLOGY \\
\hline 1 & $\begin{array}{c}\text { "Experimental study on heat transfer } \\
\text { and pressure drop in a channel with } \\
\text { triangular V-ribs," }\end{array}$ & $\begin{array}{l}\text { D. Jansangsuk, C. } \\
\text { Khanoknaiyakarn } \\
\text { and P. Promvonge, }\end{array}$ & 2010 & $\begin{array}{l}\text { transfer and pressure drop in } \\
\text { a channel with triangular V- } \\
\text { ribs }\end{array}$ \\
\hline 2 & $\begin{array}{l}\text { Thermal enhancement in a solar air } \\
\text { heater channel using rectangular } \\
\text { winglet vortex generators," }\end{array}$ & $\begin{array}{l}\text { N. Depaiwa, T. } \\
\text { Chompookham and } \\
\text { P. Promvonge, }\end{array}$ & 2010 & $\begin{array}{c}\text { enhancement in a solar air } \\
\text { heater channel using } \\
\text { rectangular winglet }\end{array}$ \\
\hline 3 & $\begin{array}{c}\text { Some thoughts on the transformation } \\
\text { of information and communication } \\
\text { technologies }\end{array}$ & lat Hequan Wu,"url & 2011 & $\begin{array}{l}\text { transformation of } \\
\text { information and } \\
\text { communication technologies }\end{array}$ \\
\hline 4 & $\begin{array}{l}\text { "Design and development of compact } \\
\text { spiral ribbed cooling unit for } \\
\text { electronic chipsets with high power } \\
\text { densities," }\end{array}$ & $\begin{array}{l}\text { C. S. Woei, C. K.th } \\
\text { Feng, W. Huiru, H. } \\
\text { C. Chin and K. J. } \\
\text { evel Ken,nent }\end{array}$ & $\begin{array}{r}\mathrm{IC} \\
2011 \\
\end{array}$ & $\begin{array}{l}\text { development of compact } \\
\text { spiral ribbed cooling unit }\end{array}$ \\
\hline 5 & $\begin{array}{l}\text { "Enhancement of forced convection } \\
\text { heat transfer from fin arrays with } \\
\text { circular perforation }\end{array}$ & $\begin{array}{l}\text { K. H. Dhanawade } \\
\text { and H. S. } \\
\text { Dhanawade, }\end{array}$ & 2011 & $\begin{array}{l}\text { heat transfer from fin arrays } \\
\text { with circular perforation }\end{array}$ \\
\hline 6 & $\begin{array}{l}\text { "Numerical investigation of flow and } \\
\text { heat transfer characteristics from an } \\
\text { impinging jet on a circular cylinder," }\end{array}$ & $\begin{array}{c}\text { Faghani, M. } \\
\text { Eskandari and E. } \\
\text { Faghani, } \\
\end{array}$ & 2010 & $\begin{array}{l}\text { Numerical investigation of } \\
\text { heat transfer characteristics } \\
\text { on a circular cylinder }\end{array}$ \\
\hline 7 & $\begin{array}{l}\text { "Numerical investigation of flow and } \\
\text { heat transfer characteristics from an } \\
\text { impinging jet on a circular cylinder," }\end{array}$ & $\begin{array}{c}\text { P. Faghani, M. } \\
\text { Eskandari and E. } \\
\text { Faghani, }\end{array}$ & 2010 & $\begin{array}{l}\text { Numerical investigation of } \\
\text { heat transfer }\end{array}$ \\
\hline 8 & $\begin{array}{l}\text { "Forced convection air cooling in } \\
\text { porous graphite foam for thermal } \\
\text { management applications," }\end{array}$ & $\begin{array}{l}\text { K. C. Leong, L. W. } \\
\text { Jin, H. Y. Li and J. } \\
\text { C. Chai, }\end{array}$ & 2008 & $\begin{array}{l}\text { convection air cooling in } \\
\text { porous graphite foam for } \\
\text { thermal management } \\
\text { applications }\end{array}$ \\
\hline 9 & $\begin{array}{c}\text { "Comparative Investigation on the } \\
\text { Cooling Effect of Swirling Impinging } \\
\text { Jet using Experimental and Numerical } \\
\text { Methods," }\end{array}$ & $\begin{array}{l}\text {. Jie-min, F. Yi-feng, } \\
\text { Y. Ying, T. Juan, H. } \\
\text { Bing-ting and C. } \\
\text { Xiao-ling, }\end{array}$ & 2007 & $\begin{array}{l}\text { Cooling Effect of Swirling } \\
\text { Impinging Jet using } \\
\text { Experimental and Numerical } \\
\text { Methods } \\
\end{array}$ \\
\hline
\end{tabular}

\section{PROBLEM IDENTIFICATIONS}

$>$ To make solar air heater more efficient there is in need of increase in heat transfer capability in SAH duct which can be done by creating turbulence in a duct by introducing artificial roughness geometry in it.

All above paper has performed in solar air heater in the different type of ribs like square, triangular, 
semicircular, circular, V-shaped, Dimple shaped, Chamfered, transverse wedge shaped, metal grit ribs, inclined ribs, multi V-shaped ribs etc.

$>$ in different type of pitch, height and different in Reynolds number. Some are performed in experimental investigation and some are in CFD analysis in different type of CFD code ANSYS FLUENT like 12.1, 14.1 etc. which have different type of heat transfer and thermo-hydraulic performance in result.

$>$ The application of artificial roughness geometry (in different shapes) has been recommended to enhance the heat transfer coefficient by several investigators.

$>$ Optimum geometry for heat enhancement study of heat transfer and fluid flow behavior in a rectangular duct for heat transfer and fluid flow.

To evaluate the effect of Reynolds number, roughness height, roughness pitch relative roughness pitch and the heat transfer coefficient and friction factor can be evaluated.

$>$ Validation of results of previous studies in the present numerical models available experimental results under similar flow conditions to results of CFD analysis.

$>$ Geometry of plate its effect on heat transfer rate and thermal resistance.

\section{METHODOLOGY}

It is a known algorithm and used in many CFD codes. SIMPLE can be used to more efficiently use computer processing time (even though there are more calculations) since it uses the correct value for pressure. For specific sorts of flow, SIMPLEC and PISO can be similarly as productive as SIMPLER. Which calculation to utilize relies upon the particular case being examined: the stream conditions, level of reliance of energy and scalars, and the particular numerical plans utilized. This flow chart is common flow chart for the all type of solution like segregated pressure based solution, pressure based coupled solution, and density based coupled solution. The coupled based method steps are shown in the flow chart.

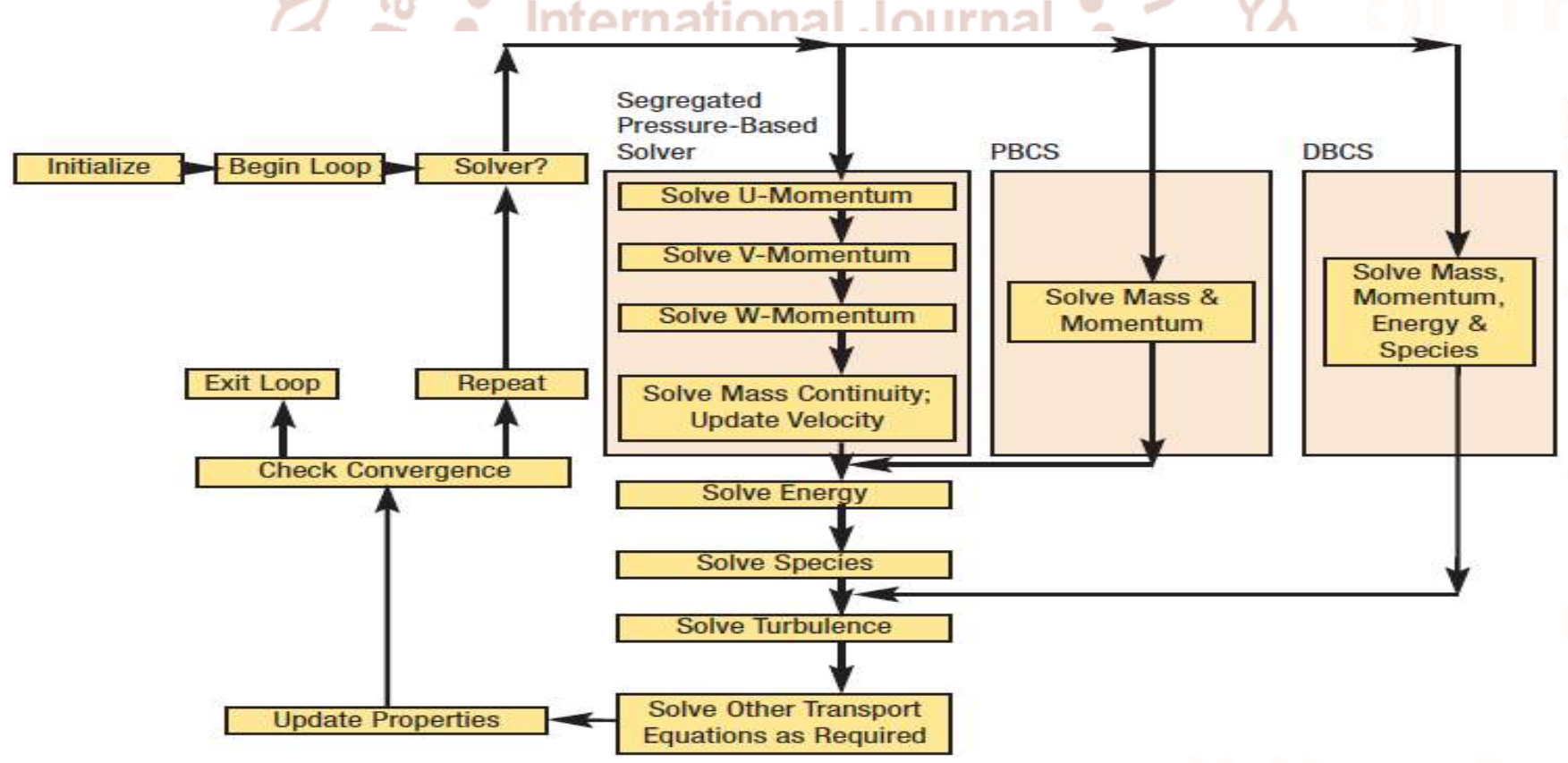

Figure 1: Flowchart illustrating FLUENT solver algorithms

\section{Where: - PBCS-Pressure based coupled solution, DBCS-Density based coupled solution}

\section{RESULTS AND ANALYSIS}

This presents the anticipated air flow speed, weight and temperature profiles amid Forced-wind current over rib geometry in the duct which were consider in this examination work. The CFD examination has been performed for blend of round and square ribs on safeguard plat of SAH and result has been contrasted and the instance of smooth duct working under similar Conditions to assess the improvement in heat transfer. The data collected using ANSYS FLUENT 14.5 included the temperature distribution, pressure distribution and airflow velocity at all node points in the model duct. We can see the following result 
International Journal of Trend in Scientific Research and Development (IJTSRD) ISSN: 2456-6470

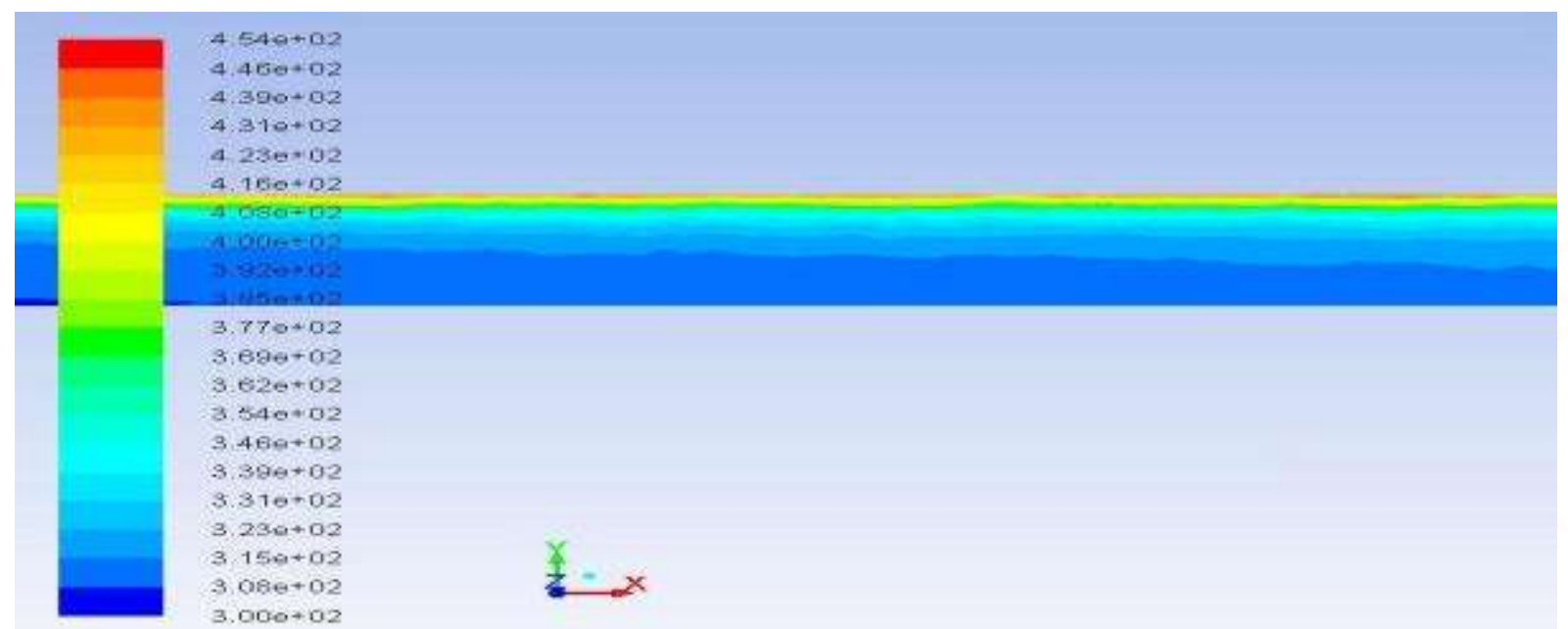

Figure 2: Temperature distribution over smooth surface

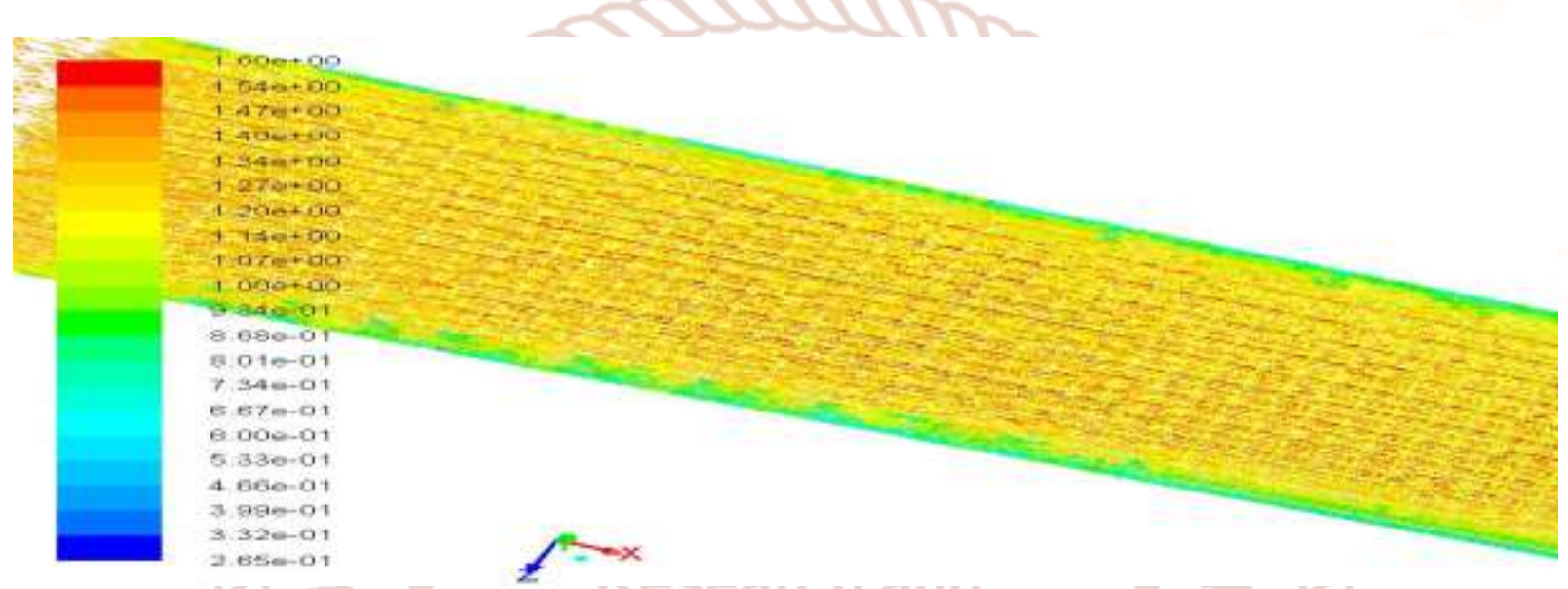

Figure 3: Velocity vector contour over smooth surface

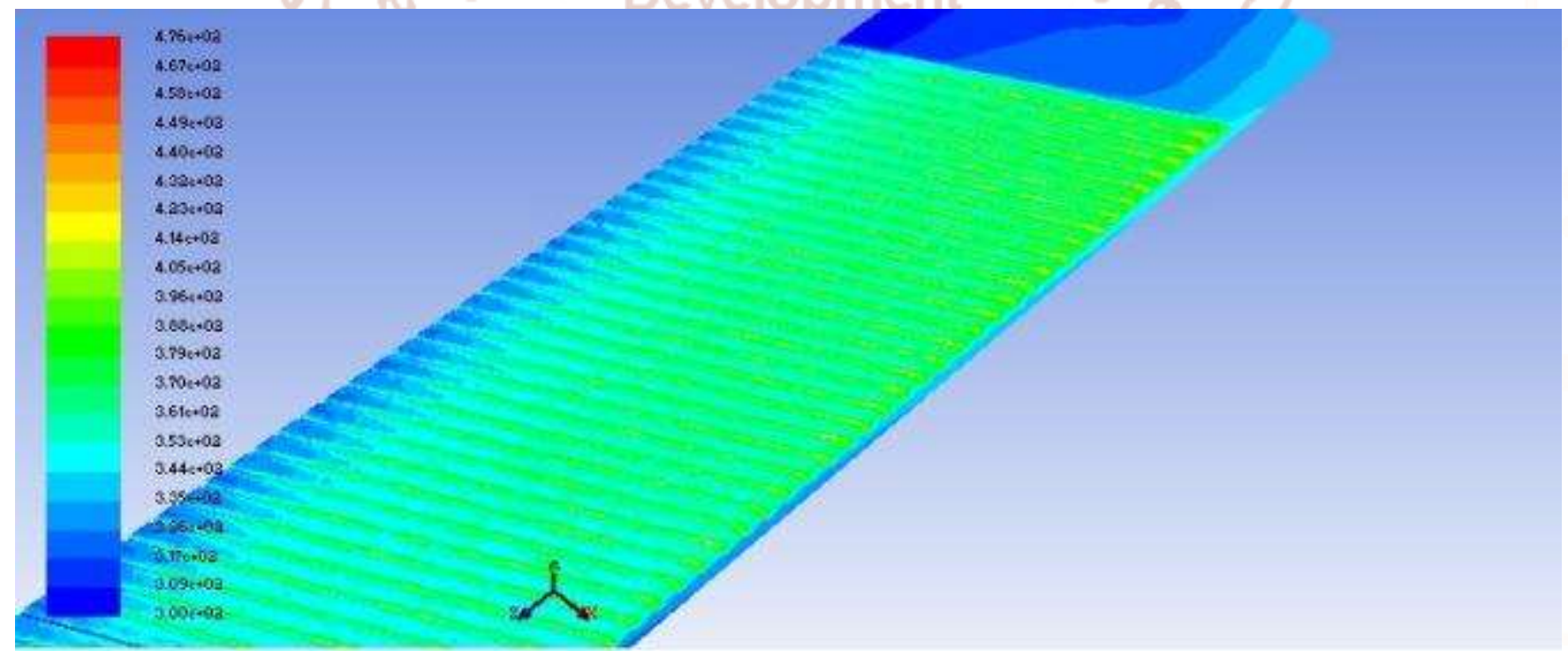

Figure 4: Temperature distribution over inclined surface

Table 1: CONTINUOUS INCLINED $P=20 \mathrm{~mm}$

\begin{tabular}{|c|c|c|c|c|c|c|c|c|c|}
\hline Ti & To & Tf & Tp & Re & Q & h & Nu & Nu(exp) & f(exp) \\
\hline 300 & 332 & 316 & 404.86 & 6000 & 344.3089 & 19.37367 & 35.06634 & 32.27887 & 0.017829 \\
\hline 300 & 325.87 & 312.935 & 379.22 & 8000 & 371.1363 & 27.99549 & 50.67184 & 47.16964 & 0.016973 \\
\hline 300 & 322.4 & 311.2 & 362.3 & 12000 & 482.0324 & 47.1656 & 85.36973 & 80.51124 & 0.015836 \\
\hline 300 & 318.65 & 309.325 & 348.56 & 14000 & 468.2242 & 59.6692 & 108.0012 & 98.65806 & 0.015424 \\
\hline
\end{tabular}


International Journal of Trend in Scientific Research and Development (IJTSRD) ISSN: 2456-6470

Table 2: DISCRETE INCLINED $\mathrm{P}=\mathbf{2 4} \mathrm{mm}$

\begin{tabular}{|c|c|c|c|c|c|c|c|}
\hline Ti & To & Tf & Tp & Re & Q & H & Nu \\
\hline 300 & 340.56 & 320.28 & 388.26 & 6000 & 436.4115 & 32.09852 & 58.09832 \\
\hline 300 & 331.25 & 315.625 & 364.96 & 8000 & 448.3188 & 45.43618 & 82.23949 \\
\hline 300 & 322.35 & 311.175 & 351.01 & 12000 & 480.9564 & 60.36857 & 109.2671 \\
\hline 300 & 317.62 & 308.81 & 341.03 & 14000 & 442.3651 & 68.6476 & 124.2522 \\
\hline
\end{tabular}

\section{CONCLUSIONS \& FUTURE SCOPE}

Average Nusselt number increases with an increase of Reynolds number. The maximum value of average Nusselt number is found to be 128.9646 for relative roughness pitch of $20 \mathrm{~mm}$ and for relative roughness height of $0.06 \mathrm{~mm}$ at a higher Reynolds number, 14000. Average friction factor decreases with an increase of Reynolds number.

The range of parameters for this study has been decided on the basis of practical consideration of the system and operating conditions. The experiment has covered a Reynolds number ( $\mathrm{Re}$ ) range of 600016000 , Relative roughness pitch $(\mathrm{P} / \mathrm{e})$ of 8,10 and 12 . Relative angle of attack $(\alpha / 90)=0.3333$. Results have been compared with the heated plate without roughness and with the earlier reported inclined rib under similar flow condition to determine the enhancement in heat transfer coefficient and friction factor.

Still there is a scope of increasing the heat transfer and fluid flow characteristics of solar air heater by providing artificial roughness on the rectangular duct. As explained and discussed the effect of roughness height and relative roughness pitch on the heat transfer characteristics we can analyse more parameters by using CFD analysis. In order to validate the present numerical study, the results have been compared with the earlier reported experimental results under similar flow conditions. In future there is many other parameter used to develop the roughness geometries will analyse to see the effect on heat transfer coefficient. Only few 3-D analyses has been done so far to analyse the different artificial roughness, hence still there is an scope of analysing different geometries with different geometrical parameters.

\section{REFERENCES}

1. D. Jansangsuk, C. Khanoknaiyakarn and P. Promvonge, "Experimental study on heat transfer and pressure drop in a channel with triangular Vribs," Proceedings of the International Conference on Energy and Sustainable Development: Issues and Strategies (ESD 2010), Chiang Mai, 2010, pp. $1-8$.

2. N. Depaiwa, T. Chompookham and P. Promvonge, "Thermal enhancement in a solar air heater channel using rectangular winglet vortex generators," Proceedings of the International Conference on Energy and Sustainable Development: Issues and Strategies (ESD 2010), Chiang Mai, 2010, pp. 1-7.

3. Hequan $\mathrm{Wu}$, "Some thoughts on the transformation of information and communication technologies," 2011 IEEE Technology Time Machine Symposium on Technologies Beyond 2020, Hong Kong, 2011, pp. 1-1.

4. C. S. Woei, C. K. Feng, W. Huiru, H. C. Chin and K. J. Ken, "Design and development of compact spiral ribbed cooling unit for electronic chipsets with high power densities," 2011 27th Annual IEEE Semiconductor Thermal Measurement and Management Symposium, San Jose, CA, 2011, pp. 231-238.

5. $=$ K. H. Dhanawade and H. S. Dhanawade, "Enhancement of forced convection heat transfer from fin arrays with circular perforation," Frontiers in Automobile and Mechanical Engineering -2010, Chennai, 2010, pp. 192-196.

6. P. Faghani, M. Eskandari and E. Faghani, "Numerical investigation of flow and heat transfer characteristics from an impinging jet on a circular cylinder," 2010 12th IEEE Intersociety Conference on Thermal and Thermo mechanical Phenomena in Electronic Systems, Las Vegas, NV, 2010, pp. 1-7.

7. K. C. Leong, L. W. Jin, H. Y. Li and J. C. Chai, "Forced convection air cooling in porous graphite foam for thermal management applications," 2008 11th Intersociety Conference on Thermal and Thermo mechanical Phenomena in Electronic Systems, Orlando, FL, 2008, pp. 57-64. 
8. Jie-min, F. Yi-feng, Y. Ying, T. Juan, H. Bingting and C. Xiao-ling, "Comparative Investigation on the Cooling Effect of Swirling Impinging Jet using Experimental and Numerical Methods," 2007 International Symposium on High Density packaging and Microsystems Integration, Shanghai, 2007, pp. 1-5

9. Z. Jie-min, F. Yi-feng, Y. Ying, T. Juan, H. Bingting and C. Xiao-ling, "Comparative Investigation on the Cooling Effect of Swirling Impinging Jet using Experimental and Numerical Methods," 2007 International Symposium on High
Density packaging and Micro system Integration, Shanghai, 2007, pp. 1-5.

10. Sahu MM, Bhagoria JL. Augmentation of heat transfer coefficient by using 90 broken transverse ribs on absorber plate of solar air heater. Renew Energy 2005; 30:2057-63.

11. Gupta D, Solanki SC, Saini JS. Thermo hydraulic performance of solar air heaters with roughened absorber plates. Solar Energy 1997; 61:33-42.

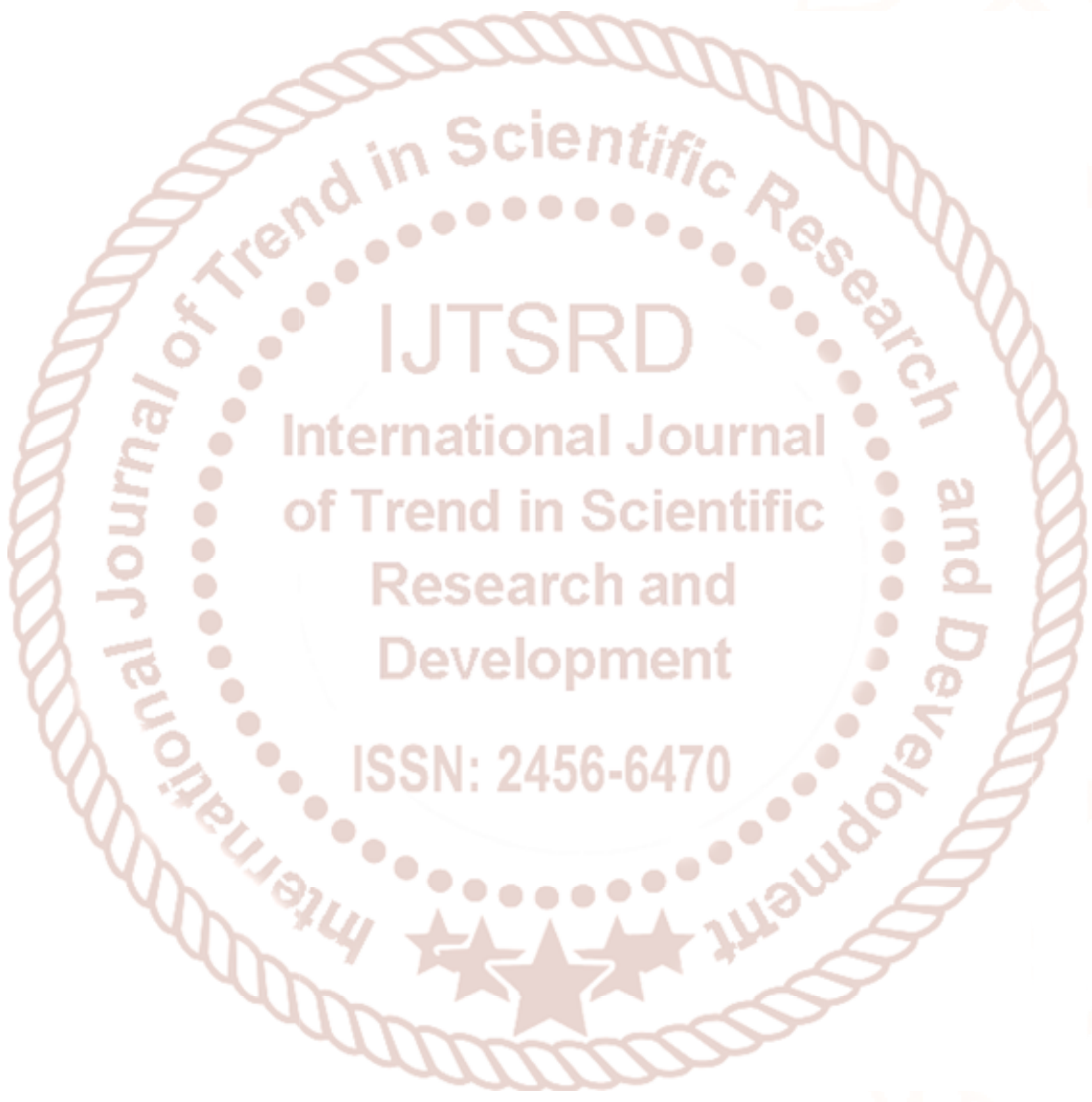

